\title{
LA FUNCIÓN REGULATTVA DEL IDEAL DE LA RAZÓN PURA
}

MARIO CAIMI

CONICET

UNIVERSIDAD DE BUENOS AIRES

Es sabido que, según las investigaciones de la Crítica de la razón pura, los conceptos, por sí solos, no producen conocimiento; son vacíos. Los conceptos puros del entendimiento tienen la función de producir la objetividad, y de este modo le dan validez objetiva a la síntesis de las intuiciones. ${ }^{1}$ Esta objetividad suministrada por los conceptos puros del entendimiento es todavía indeterminada: los conceptos puros del entendimiento son "conceptos de un objeto en general"; ${ }^{2}$ mediante ellos "no se conoce todavía ningún objeto determinado". 3

La determinación del "objeto en general", por la cual éste llega a ser un objeto determinado del conocimiento, recién se produce cuando se dan en la intuición, mediante la sensación, datos sensibles. ${ }^{4} \mathrm{El}$ concepto puro no contiene en sí los predicados necesarios para esta determinación; debe obtenerlos de alguna otra parte. ${ }^{5}$

Ahora bien, la razón produce en virtud de su misma naturaleza, ${ }^{6}$ y por lo tanto de manera necesaria, un concepto (uno solo) que parece eludir esta condición, pues contiene en sí todos los predicados necesarios para la de-

1 Crítica de la razón pura B 142. Cfr. Prolegomena, Ed. Acad. IV, 298.

2 B 128. Cfr. B 146.

3 B 150 [el subrayado es mío].

4 B 147. Cfr. Rudolf Malter: "Der Ursprung der Metaphysik in der reinen Vernunft. Systematische Ueberlegungen zu Kants Ideenlehre", en J. Kopper y W. Marx (comps.), 200 Jahre Kritik der reinen Vernunft, Hildesheim, 1981, pp. 169-210, aquí p. 200.

5 B 149.

6 B 384, B 397. Cfr. Ottokar Blaha: Die Ontologie Kants. Ihr Grundriß in der Transzendentalphilosophie, Anton Purstet, Salzburgo-Munich, 1967, p. 151. 
terminación de su objeto. ${ }^{7}$ Éste es el concepto del ens realissimum. De este concepto procede el del ideal transcendental.

Por cierto, que las ideas en general -y por consiguiente, también el ideal- son meros entes de razón, "Gedankendinge", conceptos vacíos por definición. ${ }^{8}$ Pero ello no nos autoriza a negarles toda función en el sistema de la filosofía crítica teórica. Nuestro propósito en este trabajo es determinar y describir la función regulativa que corresponde a este ideal de la razón. Para ello, primeramente, vamos a examinar la génesis del ideal en el uso lógico de la razón (lo que, por analogía con lo que se hace con los conceptos puros del entendimiento, podríamos llamar su "Deducción metafísica"); vamos a distinguir luego la función regulativa de las ideas, de la función del ideal mismo; y para ello vamos a tener que exponer la función regulativa de la idea de la totalidad de la realidad. Finalmente vamos a exponer lo que, a nuestro juicio, es la función regulativa del ideal de la razón.

\section{I. "Deducción metafísica" del ideal de la razón}

Para exponer la función regulativa del ideal es conveniente, en primer lugar, explicar cómo se origina el ideal a partir de sus condiciones lógicoformales. ${ }^{9}$ La razón produce este concepto a partir de su propia dinámica, al transformar en transcendental la forma meramente lógica del silogismo disyuntivo. Tal transformación consiste en que de aquí en adelante no se considerará tan sólo la forma lógica de la síntesis racional, sino también "el contenido" (en la medida en que éste pueda ser pensado a priori). ${ }^{10}$

7 Cfr. Svend Andersen, Ideal und Singularität. Über die Funktion des Gottesbegriffes in Kants theoretischer Philosophie, Walter de Gruyter, Berlín/Nueva York, 1983, pp. 211-212. Véase también Claude Piché, Das Ideal: Ein Problem der Kantischen Ideenlehre, Bouvier, Bonn, 1984, p. 78.

8 B 346 ss. Cfr. Svend Andersen, Ideal und Singularität, p. 181. Andersen cita la R 5724, en la que Kant establece la correspondencia de idea y ens rationis.

9 Susan Neimaann desarrolló la "Deducción metafísica" de las ideas en general, pero se abstuvo de ofrecer deducciones particulares para cada una de ellas; antes bien, encuentra que las formas de los silogismos no nos conducen a ningún concepto determinado (Susan Neimann: "Understanding the Unconditioned", en Hoke Robinson (comp.), Proceedings of the Eighth International Kant Congress, Memphis, 1995, Marquette University Press, Milwaukee, 1995, pp. 505-519, aquí pp. 506 y 507).

${ }^{10}$ B 600. Cfr. B 80, B 602. Así también Andersen p. 195. Véase también Abram Gideon, Der Begriff Transscendental in Kant's Kritik der reinen Vernunft, Marburgo, 1903; Nachdruck Darmstadt, 1977, p. 11: "Transscendental = real, inhaltlich" etc. En contra de esto W. Cramer, Gottesbeweise und ihre Kritik. Prüfung ihrer Beweiskraft, Francfort, 1967, pp. 113 s. Cramer interpreta la función transcendental de la razón - por oposición a su función lógica- como una "inversión del sentido" de la inferencia ("Umkehr der Schlußrichtung"), de tal modo, que la razón, partiendo de un juicio dado, intenta "obtener ese juicio dado, como conclusión de 
Este contenido consiste en una suma disyuntiva total (completa) de las realidades pensadas mediante predicados positivos. ${ }^{11}$

El uso lógico de la razón en el silogismo disyuntivo se produce por aplicación del "principio meramente lógico" de tercero excluido, ${ }^{12}$ que Kant presenta como "principio de determinabilidad". ${ }^{13}$ Para cualquier predicado vale que o bien es afirmado de un concepto, o bien es negado de él; independientemente del contenido que ese predicado tenga. Por tanto, todo concepto se puede determinar, ya sea positiva, o negativamente, por todos los predicados pensables. No hay aquí referencia alguna a una presunta totalidad de los predicados; ${ }^{14}$ el principio de determinabilidad tiene uni-

un silogismo". Pero Kant caracteriza expresamente este procedimiento como lógico formal en B 361 y en B 364. Cfr. Logik, Ed. Acad., IX, 134, § 87.

11 Anneliese Maier, Kants Qualitätskategorien, Pan-Verlag Kurt Metzner, Berlín, 1930 (KantStudien, Ergänzungsheft 65) hace notar (p. 12) que para Chr. Wolff "Realitas es la propiedad positiva verdadera, como tal, en el sentido más amplio". Para Baumgarten, "realidad" significa "en general, el predicado afirmativo de una cosa posible o de un concepto libre de contradicción interna" (Anneliese Maier, op. cit., p. 15). Esta concepción de la realidad como predicado positivo se ha conservado precisamente en las declaraciones de Kant acerca del ideal transcendental (Anneliese Maier, op. cit., p. 39).

12 Así interpreta Heimsoeth el principio de la determinabilidad. Véase Heimsoeth, Transzendentale Dialektik. Ein Kommentar zu Kants Kritik der reinen Vernunft, Walter de Gruyter, Berlín, 1969, p. 425. Así también Andersen, Ideal und Singularität, p. 192. Véase también Baumgarten, Metaphysica, $\S 10$.

13 B 599. El procedimiento prosilogístico correspondiente -que sigue siendo l6́gicoapunta a una premisa mayor suprema, en la que la disyunción sea completa; esta disyunción completa la encontramos en toda proposición disyuntiva de la forma $A \mathrm{v}-A$, puesto que $-A$ abarca todos los demás predicados, excepto $A$. Kant, Logik Pölitz, XXIV, 576, citado por $S$. Andersen, Ideal und Singularität, p. 187. Béatrice Longuenesse confunde de hecho determinabilidad y determinación, cuando adjudica al entendimiento la determinación completa, y la explica como comparación de cada objeto de experiencia con todos los demás, como si la determinación fuera la relación "to the complete sphere of the concept: 'object of experience" " (Béatrice Longuenesse: "The Transcendental Ideal and the Unity of the Critical System", en Hoke Robinson (comp.), Proceedings of the Eighth International Kant Congress, Memphis, 1995; Marquette University Press, Milwaukee, 1995, pp. 521-537, aquí p. 525).

14 La determinación por el entendimiento no puede operar con la unidad colectiva (totalidad) de los predicados, sino solamente con la unidad distributiva (universalidad lógica). La totalidad es sólo accesible a la razón. En contra de esto véase Béatrice Longuenesse: "The Transcendental Ideal and the Unity of the Critical System", en Hoke Robinson (comp.), Proceedings of the Eighth International Kant Congress, Memphis, 1995; Marquette University Press, Milwaukee, 1995, pp. 521-537. Longuenesse adjudica al entendimiento la completud (unidad colectiva) que corresponde sólo a la razón; habla de las relaciones "between the idea of a discursive whole of positive determinations or realities, and the complete disjunction of possible combinations of realities and negations, which would provide the complete set of possible individual things" (p. 528). Por esta confusión, Longuenesse acaba por adjudicar al entendimiento la función regulativa del ideal (p. 535: "actually, I do think that the Analytic, 
versalidad lógica, su validez no se encierra dentro de los límites de ningún dominio.

En el uso transcendental de la razón se tiene en la mira la referencia a un contenido. Mientras que el concepto podía determinarse por aplicación del principio de determinabilidad, ahora es la cosa la que ha de determinarse por aplicación del principio de determinación. Pero el principio de determinabilidad sólo presuponía la universalidad de su aplicación (presuponía ser válido para todo predicado posible); en cambio el principio de determinación omnímoda ${ }^{15}$ presupone una totalidad ${ }^{16}$ de los predicados, una síntesis disyuntiva de todas las determinaciones positivas, pensada en un concepto ${ }^{17}$ como unidad colectiva (como colección absolutamente completa) de todas las realidades. ${ }^{18}$ Se obtiene así una premisa mayor absoluta (máxima e incondicionada) del silogismo disyuntivo.

Esta premisa material es un supuesto necesario ${ }^{19}$ del principio de la determinación omnímoda. No nos detendremos aquí en el examen de este

together with its Appendix, was sufficient to offer an account for systematicity which does away with the ontological illusion carried by the ideal of pure reason").

15 Sobre este principio véase Mario Caimi: "On a Non-Regulative Function of the Ideal of Pure Reason", en Hoke Robinson (comp.), Proceedings of the Eighth International Kant Congress, Memphis, 1995; Marquette University Press, Milwaukee, 1995, pp. 539-549, aquí p. 540.

16 Esto es así porque la síntesis se efectúa mediante un concepto de la razón: B 379: "Por consiguiente, el concepto transcendental de la razón no es otro que el de la totalidad de las condiciones para un condicionado dado."

17 Sólo la conectiva lógica de la disyunción permite abarcar en una única síntesis las múltiples determinaciones, en la forma $S$ es $P$ vel $Q$ vel $R$. La conjunción, en cambio, rompería la unidad de la premisa mayor, ya que produciría una pluralidad de proposiciones de la forma $S$ es $P$ y $S$ es $Q$ y $S$ es $R$, etcétera.

18 B 600 nota: "La determinabilidad de todo concepto depende de la universalidad (universalitas) del principio de la exclusión de un medio entre dos predicados contradictorios; pero la determinación de una cosa depende de la totalidad (universitas), o del conjunto de todos los predicados posibles." Véase también B 379.

19 Peter Rohs afirma que para la determinación omnímoda de todo existente se requiere la existencia del conjunto de los predicados de las cosas, y no la "existencia del conjunto de todos los predicados posibles en general". Véase Peter Rohs: "Kants Prinzip der durchgängigen Bestimmung alles Seienden”, en Kant-Studien, no. 69, Berlín, 1978, pp. 170-180, aquí p. 172. Por el contrario, sostenemos que no es la existencia (en un enunciado asertórico), sino la presuposición (en un enunciado problemático) del conjunto absolutamente completo de todos los predicados en general, lo que se requiere para el principio kantiano; pues solamente así la idea puede cumplir su función regulativa, como explicaremos luego. Puesto que el concepto de omnitudo realitatis se origina en la razón, le corresponde la totalidad absoluta. El mismo Rohs admite que sólo se puede tener seguridad acerca de la integridad de un conjunto determinado, cuando se conoce también su complemento (Rohs, op. cit., p. 173). También reconoce que el conjunto de las realidades es objeto de una presuposición, y no de una afirmación asertórica (Rohs, op. cit., p. 175 y pass.) 
principio, pues nos interesa tan sólo trazar los rasgos principales de la generación del ideal de la razón a partir del silogismo disyuntivo. ${ }^{20}$

Consideremos para ello esa disyunción completa supuesta por el principio. Puesto que la forma lógica de la disyunción consiste en la partición de la esfera de un concepto, ${ }^{21}$ entonces la disyunción transcendental completa en la premisa mayor máxima será, según su forma lógica, la partición de la esfera del concepto de realidad. Tal partición daría por resultado un sistema de la realidad; todo concepto positivo posible (toda realidad) encontraría su lugar en este sistema. La unidad del sistema de la realidad se piensa, por lo tanto, con un solo concepto, al cual le pertenecen absolutamente todas las determinaciones positivas pensables. Éste es el concepto de la omnitudo realitatis. ${ }^{22}$

Este concepto tiene la propiedad de que puede determinar íntegramente a su problemático objeto, prescindiendo, como dijimos al comienzo, de las determinaciones sensibles de su objeto; la sensibilidad no tendría ninguna otra determinación que aportar (esto es, no tendría ningún otro predicado positivo) aparte de aquellos que ya están contenidos en el concepto. Si ocurre esta determinación omnímoda del objeto, efectuada en este único caso mediante el mero concepto, entonces el objeto, por estar íntegramente determinado, será un ente singular. Así produce la razón, en virtud de su propia esencia, y por meros conceptos determinados, ${ }^{23}$ el ideal:

Así hallamos [...] que esta idea [la idea de la omnitudo realitatis, M.C.], como concepto originario, excluye una cantidad de predicados, que, por ser derivados, ya están dados por otros, o que no pueden coexistir, ${ }^{24}$ y que ella se purifica hasta [tornarse] un concepto íntegramente determinado a priori, y que con ello se vuelve el concepto de un objeto singular, determinado íntegramente por la sola idea, el que por lo tanto debe llamarse un Ideal de la razón pura." ${ }^{25}$

20 Béatrice Longuenesse (op. cit., pp. 524-525) señala la importancia del juicio indefinido en la generación del ideal.

21 B 604; Cfr. Logik, Ak. Ausg. IX, pp. 104 y 106.

22 B 603/604: "Si, por lo tanto, se le pone a la determinación omnímoda, en nuestra razón, un sustrato transcendental por fundamento, [sustrato] que contiene lo que podríamos llamar todo el acopio de materia del cual pueden tomarse todos los predicados posibles de las cosas, entonces este sustrato no es otra cosa que la idea de una totalidad de la realidad (omnitudo realitatis)."

23 B 598: "Tal es el caso del ideal de la razón, que siempre debe [.. . ] basarse en conceptos determinados."

24 Los predicados positivos son más originarios que cualquier negación, de modo que en la síntesis originaria no puede haber contradicciones (para las que se requerirían negaciones). El concepto de una síntesis originaria completa de todos los predicados positivos (por lo tanto, el concepto de una omnitudo realitatis) no contiene contradicción, es lógicamente posible. B 603; cfr. Fortschritte der Metaphysik, Ak. Ausg. XX, 302.

25 B 601/602. 


\section{La función regulativa de la omnitudo realitatis}

De acuerdo con las declaraciones de Kant en la introducción a la Dialéctica (B 365/366), queda establecido que la razón tiene un uso lógico (pero entonces "solamente subalterno") o tiene también un uso transcendental, el cual conduce inevitablemente al engaño por la ilusión transcendental.

Se nos plantea la pregunta: ¿cuál es, en particular, la función lógica del ideal, y en qué consiste su uso transcendental, si acaso tiene alguno? Para responder a estas preguntas, vamos a empezar por plantearnos la función de la idea de omnitudo realitatis, y en primer lugar, su explicación en el "Apéndice a la Dialéctica transcendental".

En el Apéndice de la Dialéctica, Kant asigna a las ideas una función regulativa. Podemos entonces suponer que la función regulativa de la idea de omnitudo realitatis, en particular, está descrita allí. Sólo que nos encontramos ante una dificultad: es que allí se trata de la función regulativa de unas máximas de la razón; pero es difícil decidir cuál de estas máximas es la que corresponde precisamente a la idea que nos ocupa. ${ }^{26}$ Encontramos, sin embargo, en las formulaciones que el mismo Kant ofrece, indicaciones que nos permiten establecer esa correspondencia entre la idea de Dios y uno de los principios regulativos. Sabemos que esa idea se ha originado en el silogismo disyuntivo, y que representa el término del infinito regreso prosilogístico hacia una premisa disyuntiva absoluta y completa, que contendría la suma disyuntiva de todas las propiedades que pudieran predicarse, o de todas las realidades (en el sentido de predicados positivos posibles). Al enunciar el principio de afinidad, Kant indica expresamente que ese principio se refiere a la unidad racional de las propiedades (es decir, de los predicados positivos), ${ }^{27}$ y que se refiere a una unidad racional tal, que no haga abstracción de

26 B 685 . Gideon afirma que no hay correspondencia entre los principios regulativos de homogeneidad, especificación y afinidad, y las ideas. Aquellos principios serían más bien todos explicitaciones de una única idea, la idea de Dios. Abram Gideon, Der Begriff Transscendental in Kant's Kritik der reinen Vernunft, Marburgo, 1903 (Darmstadt, Wissenschaftliche Buchgesellschaft, 1977) p. 136, n. 1. En el mismo sentido, Zocher sostiene que se trata de dos concepciones de las ideas completamente diferentes, incomparables entre sí: las "tres formas de la idea" en el Apéndice a la Dialéctica "no tienen nada que ver, de manera inmediata, con las tres ideas de la Dialéctica, que son cuasi-objetivas y que hacen posible la ilusión transcendental". Rudolf Zocher, "Zu Kants transzendentaler Deduktion der Ideen der teinen Vernunft", en Zeitschrift für philosophische Forschung, Meisenheim/Glan, 1958, pp. 43-58, aquí p. 55. El mismo autor reconoce tan sólo una correspondencia general entre la idea de Dios y la unidad sistemática, op. cit., p. 57, n. 14.

27 "El parentesco de lo múltiple, sin perjuicio de su variedad, bajo un principio de unidad, no concierne solamente a las cosas, sino que aún más [concierne] a las meras propiedades y poderes de las cosas." (B 690.) Esto habría que referirlo a las realidades que conforman la omnitudo realitatis. También vincula Kant (en B 600 nota) el ideal con la afinidad. Por la afinidad, el género supremo deja de ser el más abstracto, para convertirse en el más rico, abarcando 
las características individuales que distinguen los predicados unos de otros dentro de la multiplicidad que forman: "sin perjuicio de sus diferencias"; se trata de una unidad sistemática colectiva. Hemos observado ${ }^{28}$ que la unidad sistemática colectiva de predicados positivos sólo puede formularse como disyunción. Hay aquí entonces una concordancia manifiesta entre el principio de afinidad y el concepto de la razón que estamos tratando.

Consideraremos, entonces, como formulación de la función regulativa de esta precisa idea, a la "ley de la afinidad de todos los conceptos" o principio de afinidad, o principio de continuidad de las formas.

La función regulativa de la idea de la continuidad de las formas consiste en que esta idea hace posible la unidad sistemática del conocimiento de la Naturaleza, pues en esa idea se piensa a priori la completa interconexión de todos los conocimientos empíricos particulares, en un sistema. ${ }^{29}$ Esta regulación se ejerce sólo sobre la forma de la multiplicidad de los conocimientos; esa multiplicidad deja de ser un agregado, para pasar a ser un sistema. Es:o ocurre porque la interconexión (pensada, a priori, como consumada de manera absoluta y definitiva) se propone como fin, y todos los elementos en los que consiste la multiplicidad se ordenan respecto de aquel fin. ${ }^{30}$

El principio de afinidad por el cual se efectúa esta unidad racional es meramente lógico. Pero no tiene, como tal, validez por sí solo, sino únicamente en relación con un principio transcendental igualmente originado en la razón, mediante el mismo mecanismo por el cual se obtuvo el principio lógico de la afinidad: originado en el silogismo disyuntivo. ${ }^{31}$ Este principio

toda la realidad sin que haya intersticios (saltos) de vacío (B 687). Así, el principio de afinidad o de continuidad viene a ser el que corresponde a la omnitudo realitatis. Es sorprendente que Andersen, en su tratamiento del ideal, deje de lado expresamente el principio de la afinidad (Andersen, op. cit., p. 226).

28 Véase nuestra n. 17.

29 B 673. Cfr. B 860/861.

30 Cfr. Norbert Hinske, "Die Wissenschaften und ihre Zwecke. Kants Neuformulierung der Systemidee", en Akten des Siebenten Internationalen Kant-Kongresses, Kurfürstliches Schloß zu Mainz, 1990, G. Funke (ed.), Bouvier, Bonn, 1991, pp. 157-177, especialmente pp. 173-174.

31 B 688: "Esta ley lógica del continui specierum (formarum logicarum) presupone una ley transcendental (lex continui in natura) [... ] Por tanto, esta ley debe basarse en fundamentos transcendentales puros, y no en fundamentos empíricos. Pues en este último caso, vendría después de los sistemas; pero es prećisamente lo que ante todo ha producido lo sistemático del conocimiento de la naturaleza." (Hemos suprimido los subrayados del original.) El principio lógico no vale por sí solo, pues podría llevar a una organización caprichosa del conocimiento, que no concordara con la realidad, o que fuera aun contraria a ésta: "Pues en ese caso procedería precisamente contra su propia finalidad, al proponerse por meta una idea que contradijese [... ] las disposiciones de la Naturaleza." (B 679.) Por eso, sólo vale bajo la suposición necesaria del principio transcendental, que enuncia la validez (problemática) de la unidad sistemática en 
transcendental de afinidad no es, por lo tanto, vacío, sino que tiene una referencia (aunque sólo problemática) ${ }^{32}$ a la Naturaleza misma. No es solamente una ley continui formarum logicarum, sino también una lex continui in natura. ${ }^{33}$

El principio transcendental de afinidad consiste en la suposición necesaria de una infinitud de propiedades (realidades) de las cosas (aun cuando la experiencia muestre más bien una discontinuidad entre estas propiedades).$^{34}$ ¿Cómo se modifica la función regulativa que hemos asignado a la idea de la omnitudo realitatis, cuando tomamos en cuenta el sentido transcendental del principio de afinidad? La función regulativa que corresponde específicamente a esa idea va, ahora, más allá de la mera clasificación y subordinación de especies y géneros en una unidad sistemática formal. Esta clasificación corresponde al principio solamente lógico usado por los investigadores de la Naturaleza. Pero el principio transcendental, en el cual el principio lógico se basa, permite una extensión del uso de la razón, que entonces no solamente abarca la Naturaleza clasificable según principios teleológicos (como en ocasiones pareciera sugerirlo Cohen) ${ }^{35}$ sino que se extiende a todo objeto empírico singular.

Este nuevo modo como la razón ejerce ahora su función regulativa lo podemos adelantar diciendo: la razón hace posible la ampliación infinita del conocimiento determinado de cada objeto empírico. Esta función regulativa se realiza gracias a la suposición del principio de la determinación omnímoda. Enseguida explicaremos esta afirmación.

La determinación omnímoda tenía en la tradición racionalista dos significados que coexistían. En primer lugar, se la entendía como principium

la Naturaleza misma. El principio transcendental, a su vez, funda su validez en la posibilidad de la experiencia: sin la suposición transcendental no habría uso empírico del entendimiento. (B 679).

32 Esta referencia problemática la expresa Kant diciendo que no se afirma que eǹ la Naturaleza reine el orden racional sistemático, pero se supone necesariamente esa ordenación de la Naturaleza, pues de otro modo no sería posible el conocimiento empírico. (B 689.) No se trata tampoco de una mera hipótesis acerca de la eventual organización de la Naturaleza, sino de una suposición necesaria por motivos transcendentales. Cfr B 682 (para el principio de homogeneidad) y B 685 (para el principio de especificación).

33 B 688 . Véase Mario Caimi: "über eine wenig beachtete Deduktion der regulativen Ideen", en Kant-Studien, no. 86, 1995, pp. 308-320.

34 Pensada con un concepto de la razón, esta infinitud se concebirá como una totalidad absoluta de las realidades: vendrá a ser la omnitudo realitatis. Se confirma así como correcta nuestra elección de este principio de afinidad como el correspondiente a esa idea de la razón.

35 Hermann Cohen, Kants Theorie der Erfahrung, 3a. ed., Bruno Cassirer, Berlín, 1918, p. 710: "Las leyes empíricas particulares no se proponen absoluta y únicamente caracterizar lo material de las leyes del movimiento, sino lo orgánico de las formas de la Naturaleza." 
individuationis, ${ }^{36}$ y luego como fundamento del complementum possibilitatis (para la existencia) ${ }^{37}$ (si bien ambos criterios se entremezclan). ${ }^{38}$

La filosofía crítica sustituye estos dos criterios puramente racionales, por otros que no se basan sólo en la razón ni en el entendimiento puro, sino que toman en cuenta también la sensibilidad. ${ }^{39} \mathrm{El}$ ente singular no se definirá como tal solamente por los predicados de su concepto, sino porque se le puede asignar un lugar preciso en el espacio y un momento único en el tiempo. ${ }^{40}$ (Solamente un objeto deriva su singularidad de la completa determinación de su concepto -que es el único concepto que puede

36 Cfr. Wolff, Ontologia, § 227: "Cum entia singularia existant, evidens est, Ens singulare, sive Individuum esse illud, quod omnimode determinatum est." Allí también, § 229: "Principium individuationis est omnimoda determinatio eorum, quae enti actu insunt. Etenim cum ens singulare sive individuum sit, quod omnimode determinatum est ( $§ 227$ ); ex eo intelligimus, cur ens A individuum sit, quod idem omnimode determinatum sit."

Así también Baumgarten, Deutsche Metaphysik $§ 114$ (según W. Cramer, Gottesbeweise und ihre Kritik. Prüfung ihrer Beweiskraft, Klostermann, Francfort, 1967, p. 145).

37 Wolff, Ontologia, § 226: "Quicquid existit vel actu est, id omnimode determinatum est." Y también en el § 235: "Ens universale existere nequit. Ens enim universale omnimode determinatum non est ( $\S 230$ ). Quamobrem cum existere nequeat nisi quod omnimode determinatum est ( $\S 226$ ); ens universale existere nequit." También en la Metaphysica latina de Baumgarten se lee en el $\S 54$ : "Possibile praeter essentiam [... ] aut est determinatum, qua omnes affectiones etiam in ipso compossibiles, aut minus [... ] Illud est ACTVALE [... ], hoc NON ENS [... ] PRIVATIVVM (mere possibile) [. . . ] vocatur." Así también Kant en Opus postumum I, 603 (según P. Rohs, op. cit., p. 177).

38 Cfr. Andersen, op. cit., p. 197.

39 En el desarrollo de este principio crítico de individuación consiste la crítica de Kant al principio leibniziano de la identidad de los indiscemibles. Véase Fortschritte der Metaphysik, Ed. Acad. XX, 282. La admisión del principio de individuación puramente racional conduciría a las paradojas llamadas "de las contrapartidas incongruentes". Sobre la vinculación de la discusión kantiana del principio de la identidad de los indiscernibles, y la paradoja de las contrapartidas incongruentes, véase Vaihinger, Kommentar zu Kants Kritik der reinen Vernunft, 2a. ed., Stuttgart, 1922; Aalen, 1970, t. Il, p. 529 y ss. En Prolegomena, § 13, Ed. Acad. IV, 285/286, se vale Kant de esa paradoja para mostrar que la intuición es una fuente de conocimiento independiente del entendimiento, y de igual rango que éste.

40 Andersen sostiene que el principio de determinación omnímoda es, para Kant, un principio de individuación que corresponde, "en el plano del pensar", a la individuación por intuición: "Respecto a la individuación propiamente dicha, a la intuición, como condición de conocimiento, [... ] le corresponde la idea de la razón de la determinación omnímoda." (Svend Andersen, Ideal und Singularität, p. 237. Ambos principios coexisten, según este autor, como "individuación demostrativa" e "individuación descriptiva" (pp. 231, 232). Pero para sostener esto, Andersen debe, por una parte, renunciar a lo singular como tal (anulando así la individuación que pretende lograr): lo singular se piensa con una idea, y adquiere el carácter de "objeto en general" (p. 231). Y por otra parte, tiene que introducir "conceptos infimos" convencionales, en contradicción con el principio de especificación (pp. 234-235). En realidad el principio puramente racional de individuación sigue vigente en la filosofía crítica, pero sólo en un caso, que es precisamente el del ens realissimum. 
determinarse íntegramente a priori-; es el ens realissimum) ${ }^{41}$ Tampoco la existencia efectiva se definirá, en adelante, como determinación omnímoda conceptual. ${ }^{42}$ Por consiguiente, ninguna de las funciones tradicionales del principio de omnimoda determinatio será la que describa adecuadamente la nueva función de este principio; deberemos plantearnos de nuevo la pregunta por su función regulativa.

III. La regulación que ejerce la razón sobre el conocimiento de objetos empíricos consiste en proponerle al entendimiento la determinación de estos objetos como tarea infinita

El conocimiento empírico de objetos consiste en la progresiva determinación del objeto mediante la atribución -o negación- de propiedades (realidades) obtenidas de la experiencia. ${ }^{43}$ Este progreso en la determinación del objeto de conocimiento está guiado por la idea de la totalidad absoluta de las determinaciones, esto es, por la idea de la omnitudo realitatis, que hace que esta determinación empírica tenga cierta característica, a saber: que nunca se dé por concluida mientras no alcance aquella totalidad ${ }^{44}$ (lo que equivale a exigir que la tarea de determinación empírica sea infinita: cualquier determinación conceptual de un objeto empírico resulta incompleta, al compararla con aquella totalidad absoluta de las determinaciones).

Ahora bien, la guía que la idea presta a la actividad del entendimiento podría quizá conducir a un extravío (pues tal guía está originada en la razón, que nada sabe de cómo son en realidad los objetos a los que la actividad del

41 Heimsoeth, Transzendentale Dialektik, p. 443. P. Rohs hace notar que en el Opus postumum se presenta otro caso de determinación omnímoda mediante el mero concepto, a saber: el éter (Wärmestoff). P. Rohs, op. cit., p. 177. La determinación omnímoda funciona aquí como criterio de existencia, y no de individuación.

42 Rohs advierte que en el Opus postumum Kant parece sostener "que se pudiese inferir, de la determinación omnímoda, la existencia [... ] Aparentemente Kant no advierte que aquí incurre en contradicción con lo que él mismo había sostenido en la Crítica: que la existencia no es un predicado real". Peter Rohs, op. cit., p. 177.

43 B 609 s.: "Pero aquello en lo cual/está dado lo real de todos los fenómenos, es la experiencia única omniabarcadora."

44 Respecto del regreso en la cosmología dice Kant: "El principio de la razón es, entonces, propiamente sólo una regla, que manda un regreso en la serie de las condiciones de los fenómenos dados, regreso al que jamás le está permitido detenerse en algo absolutamente incondicionado." (B 536/537.) "Es [... ] un principio de continuar y ampliar la experiencia lo más posible, [principio] según el cual ningún límite empírico debe valer por límite absoluto." (B 537.) Esto se aplica también a nuestro caso, puesto que se aplica, en general, para las ideas de la razón; véase B 717/718: "Se puede llamar así [a saber: ignava ratio M.C.] a todo principio que haga que uno dé por absolutamente acabada su investigación de la naturaleza, en cualquier estado en que esté/, de modo que la razón se entregue al reposo, como si hubiese llevado enteramente a término su negocio." 
entendimiento se refiere) ${ }^{45}$ La validez de la guía está condicionada por la suposición transcendental de la omnitudo realitatis, esto es, por el supuesto de que hay una totalidad de todos los predicados posibles, de modo que la continuación del trabajo de determinación más allá de las determinaciones empíricas alcanzadas en cada caso, no sea una exigencia quizá caprichosa de la razón, sino una aproximación a un efectivo conocimiento mayor y más completo. ${ }^{46}$ Pero esta suposición transcendental es sólo relativa: sirve sólo para hacer válido el uso de la guía de la razón respecto del conocimiento empírico, y no es una aserción de la efectiva existencia de aquella totalidad de la realidad. ${ }^{47}$ Se la debe distinguir de la afirmación lisa y llana

45 B 679: "Pues en ese caso, ella [scil. la razón] procedería precisamente contra su propósito, al proponerse por meta una idea que estaría enteramente en contradicción con la disposición de la Naturaleza."

46 En el mismo sentido afirma P. Rohs: "Lo real de todo fenómeno (el conjuinto de la realidad empírica) debe ser dado, si ha de ser posible la determinación omnímoda." P. Rohs, $o p$. cit., p. 175. La totalidad de la materia del pensar viene a ser así una condición material $a$ priori a la cual "debe ser remitido, por lo que respecta a su contenido, todo pensar de los objetos en general". (B 604.) Ya en 1754 advirtió Kant que la materia es una condición del pensar (Principiorum primorum cognitionis metaphysicae nova dilucidatio, sec. II, proposición VII, Ed. Acad. I, 395). Pero sus declaraciones en el capítulo del ideal transcendental remiten más bien a la argumentación del escrito sobre "El único fundamento posible para una demostración de la existencia de Dios". (Cfr. Dieter Henrich, Der ontologische Gottesbeweis. Sein Problem und seine Geschichte in der Neuzeit, J.C.B. Mohr, Tubinga, $1967^{2}$ (1960) p. 140). En ese escrito distingue Kant posibilidad lógica y posibilidad real. Un concepto es lógicamente posible si no contiene contradicción, es decir, si no contiene predicados que se contradigan. Posibilidad real tiene un concepto, si en él hay realidades que pueden ser pensadas. Si no hay dato alguno, si no hay materia que pueda ser pensada, desaparece también toda posibilidad (Ed. Acad. II, 78). Por tanto, si el concepto no ha de ser una palabra vacía, sus elementos deben ser dados a nuestro pensamiento (Ed. Acad. II, 79 ss.).

La existencia de al menos una realidad es, en 1763 , condición de la posibilidad real. Pero ocurre que toda realidad singular determinada es tan sólo el resultado de la limitación de la realidad completa, mediante determinaciones que no son propiamente más que limitaciones (B 604; cfr. Ed. Acad. II, 87). De este modo, la realidad omniabarcadora se presupone siempre, como condición de la posibilidad real de cualquier concepto. La "materia de toda posibilidad", pensada mediante el concepto de la omnitudo realitatis, viene a ser entonces "presuposición transcendental" de la aplicabilidad del principio de la determinación omnímoda (B 600/601).

Que el conocimiento depende de una condición material ha sido destacado recientemente por Bernd Dörflinger: "Zum Status der Empfindung als der materialen Bedingung der Erfahrung", en Gerhard Funke (comp.), Akten des Siebenten Internationalen Kant-Kongresses, Kurfürstliches Schloß zu Mainz, 1990, Bouvier, Bonn, 1991, pp. 101-117.

47 B 605/606. La suposición transcendental no es tampoco una hipótesis que pudiera eventualmente ser confirmada; sino que ella hace posible la formulación de hipótesis acerca de los objetos empíricos. La fundamentación de esta suposición transcendental (como necesaria para la posibilidad del conocimiento empírico) la ofrecerá Kant en el "Apéndice a la Dialéctica transcendental. Del uso regulativo de las ideas de la razón pura", especialmente en B 679 . 
de la totalidad de la realidad como dada. ${ }^{48} \mathrm{El}$ hecho de que sea necesario efectuar la suposición no nos autoriza a convertirla en una afirmación de aquello que suponemos. Tomar la suposición necesaria por una realidad efectivamente existente sería incurrir en la ilusión transcendental; aquella omnitudo realitatis no existe como una totalidad absoluta de realidades; pero la suposición de esa totalidad es necesaria para el conocimiento de los objetos empíricos.

Así, la omnitudo realitatis se presenta como una condición material del conocimiento; su función regulativa consiste en hacer posible el progreso infinito del trabajo empírico de determinación, por el cual se conoce al objeto singular como tal. ${ }^{49}$ La suposición de la omnitudo realitatis no es solamente una condición del conocimiento completo (como afirma P. Rohs) ${ }^{50}$ sino que es condición de la deficiencia de cualquier determinación: condición para que se considere incompleta cualquier determinación (para que no se considere acabada la determinación -el conocimiento empírico- de un objeto ya en un momento inicial del proceso de determinación). Sólo con esa condición hay progreso en la determinación empírica (aun en la determinación incompleta). Si no fuera por ella, cualquier estadio de la determinación se podría considerar definitivo. Por tanto, la omnitudo realitatis es condición del progreso del conocimiento empírico. La determinación conceptual es una tarea infinita que nunca podrá estar completa; así lo exige la naturaleza misma de la determinación racional, que postula que no hay especies infimas, que puedan referirse inmediatamente a individuos, sino que toda determinación conceptual debe dejar paso a una ulterior más precisa. Pero así lo exige también la idea de la totalidad de la realidad, que se propone como meta o como patrón de medida de la determinación empírica.

43 B 605/606: "Va de suyo que la razón, para esta intención suya, a saber, para representarse tan sólo la necesaria determinación omnímoda de las cosas, no presupone la existencia de un ente tal, correspondiente al ideal, sino que presupone solamente la idea de él." Véase sobre esto D. Henrich, Der ontologische Gottesbeweis. Sein Problem und seine Geschichte in der Neuzeit, Tubinga, 1967 (1960) p. 142, y Anneliese Maier, Kants Qualitätskategorien, p. 40.

Si las realidades estuvieran dadas en la idea de la omnitudo realitatis, se podría conocer cualquier cosa a priori, a partir de principios; para ello se requeriría determinar la cosa, mediante negaciones, a partir de aquel todo de realidades, como un escultor obtiene las formas en un bloque de mármol (Fortschritte, Ed. Acad. XX, 302).

49 Precisamente esta función: la de hacer posible el conocimiento del objeto singular mediante una determinación progresiva infinita, es la que Andersen asigna al ideal transcendental: Svend Andersen, Ideal und Singularität (op. cit.), p. 194, 215 s., 231 s., y passim.

50 "El principio [de la determinación omnímoda] no se aplica a las condiciones de posibilidad de la experiencia en general, sino a las condiciones de posibilidad de una experiencia completa." Peter Rohs, op. cit., p. 172. 


\section{La función regulativa propia del ideal}

Hasta ahora nos hemos servido solamente de la expresión "omnitudo realitatis", y hemos eludido el empleo de la expresión "ens realissimum". Lo hicimos así para hacer notar que la determinación omnímoda puede ser efectuada por la idea de la omnitudo realitatis, sin recurrir al ens realissimum (como ente singular). ${ }^{51}$ La cuestión que ahora nos ocupará es si este ens realissimum acaso cumple alguna función que no puede ser efectuada por la idea de la omnitudo realitatis.

La tercera idea, tal como la hemos descrito en las páginas anteriores, se distingue de las otras dos ideas solamente por su diferencia específica. Pero Kant no distingue el ideal de las ideas sólo de manera específica (como una especie dentro de un género común), sino que lo distingue expresamente como un producto de la razón de orden nuevo y superior: debemos "admitir que la razón humana no solamente contiene ideas, sino también ideales. ..",52 y más todavía: "Pero aún más que la idea, parece estar alejado de la realidad objetiva aquello que yo llamo el Ideal. .."53 Si ello es así, tendremos que modificar lo que hemos dicho hasta ahora, para dar cuenta de este rango peculiar del ideal.

El ideal se caracteriza porque es una cosa singular, un individuo; Kant entiende expresamente por ideal "la idea, no tan sólo in concreto, sino in individuo, esto es, como una cosa singular, sólo determinable, o aun determinada, por la idea". ${ }^{54} \mathrm{El}$ concepto de la razón se vuelve cosa singular mediante la determinación omnímoda; Kant explica esto ya en la sección primera, introductoria, del capítulo del ideal, con ayuda del concepto de hombre. Por ampliación de las propiedades necesariamente contenidas en ese concepto "hasta la completa congruencia con sus fines" 55 alcanzamos la idea de humanidad. Pero además de esas propiedades que necesariamente

51 B 608: "todas las consecuencias que se siguen de tal ideal, no afectan la determinación omnímoda de las cosas en general, solamente para la cual era necesario el ideal, y no tienen el más mínimo influjo sobre ella." Cfr. P. Rohs, op. cit., p. 174: "A la idea del conocimiento completo le pertenece la idea de un conjunto completo de predicados posibles, pero no la idea de un ens realissimum." De modo parecido se expresa R. Zocher, op. cit., p. 48 s.

52 B 597.

53 B 596.

54 B 596. Cfr. Refl. 5759, Ed. Acad. XVIII, 346, en la que se observa el tránsito de la concepción de la determinación omnímoda como criterio de existencia, a la concepción de la determinación omnímoda como criterio de individuación: "Todo lo que existe está íntegramente determinado. La cosa absolutamente necesaria debe considerarse como determinada por su concepto como existente, y en consecuencia, [debe considerarse] como integramente determinada. Deus est conceptus singularis; que a Él cada uno de sus predicados se le atribuya de manera necesaria, y que sea determinable vnico modo, no demuestra la necesidad de su existencia."

55 B 596. 
le pertenecen al concepto, hay muchas otras (en verdad, están todas las restantes propiedades, tanto las que pueden aplicarse al concepto, como las que habrá que negar de él). Éstas son las que, junto a las propiedades necesarias, intervienen en la determinación omnímoda de la idea. Sólo si la idea está determinada respecto de todos los predicados posibles y pensables, se vuelve el concepto de un individuo singular, ${ }^{56}$ que no es un mero ejemplo tomado del mundo fenoménico (el cual nunca alcanzaría la perfección propia de la idea), ${ }^{57}$ sino un ideal de la razón.

De este ejemplo de Kant parecería poder inferirse que siguiendo el procedimiento aquí presentado (la determinación omnímoda de un concepto de la razón), se podrían pensar los ideales de todas las cosas. No es así, porque la determinación omnímoda de las cosas empíricas no puede efectuarse de una sola vez. Los predicados para esa determinación sólo pueden obtenerse de la experiencia, a medida que se van presentando en ella. Esto significa que para determinar objetos sensibles hay que salir del concepto para buscar en la experiencia cada nuevo predicado. ${ }^{58}$ La determinación omnímoda se convierte así en una tarea infinita. Por ello, la razón humana sólo puede producir un único ideal, en sentido propio, ya que sólo en un único caso es posible la determinación omnímoda a priori, por medio del solo concepto. ${ }^{59}$

Podemos precisar entonces nuestra caracterización del ideal, agregando que es la única cosa singular cuya determinación completa se produce por el concepto solamente. La razón piensa "un objeto [. . . ] que ha de ser determinable íntegramente por principios. . " $" 60$ Esto es posible solamente en un único caso, a saber, en el caso del ens realissimum. ${ }^{61}$

56 De acuerdo con el principio de individuación admitido por Wolff y por Baumgarten.

57 B 598.

58 A 8; B 12. Se obtiene así un juicio sintético a posteriori.

59 B 604: "Pero es también el único ideal propiamente tal, del que es capaz la razón humana; porque sólo en este único caso, un concepto, en sí mismo universal, de una cosa, es determinado íntegramente por sí mismo, y es reconocido como la representación de un individuo."

60 B 599 [el subrayado es mío]. Que sea "determinable íntegramente por principios" quiere decir que en su determinación aparecen solamente conceptos y no intuiciones, de modo que la determinación se produce como una deducción a partir de principios. Cfr. B 357: "Por ello, llamaré conocimiento por principios a aquél en el que conozco lo particular en lo universal, por conceptos. Así, todo silogismo es una forma de la derivación de un conocimiento a partir de un principio." Véase también B 357/358: "El entendimiento no puede, en modo alguno, producir conocimientos sintéticos a partir de conceptos, y éstos son, propiamente, los que llamo, en sentido absoluto, principios."

61 B 604: "Es ist aber auch durch diesen Allbesitz der Realität der Begriff eines Dinges an sich selbst; als durchgängig bestimmt, vorgestellt, und der Begriff eines entis realissimi ist der Begriff eines einzelnen Wesens...", como si dijera: "Pero también por esta posesión de toda la realidad, se representa el concepto de una cosa en sí misma íntegramente determinada, y el 
Por consiguiente, lo que nos ocupa ahora es un ideal que no es solamente una idea, sino una cosa —-como quiera que haya de entenderse esto-que está íntegramente determinada por su concepto. El concepto que determina el ideal es el concepto racional de la omnitudo realitatis. ${ }^{62}$ El ideal se genera a partir de la idea de la omnitudo realitatis porque esa idea contiene en sí todos los predicados que designan una realidad; y por ello, para la determinación completa del objeto pensado en la idea no es necesario buscar ulteriores determinaciones fuera del concepto; pues no las hay. Al objeto pensado con la idea le corresponde a priori todo predicado pensable ${ }^{63}$ con tal que sea originario (que no sea derivado, y por lo tanto, que no sea una negación). ${ }^{64}$ Así, a partir del concepto racional de omnitudo realitatis, se origina el ideal de la razón: el ens realissimum. La determinación omnímoda (absolutamente completa) es el motivo por el cual lo que surge es una cosa singular.

concepto de un entis realissimi es el concepto de un ente singular... " Rohs señala que en el Opus postumum se presenta un objeto empírico que puede ser determinado íntegramente de manera analítica: el éter. P. Rohs, op. cit., p. $177 \mathrm{~s}$.

62 B 603: la determinación omnímoda de una cosa singular requiere, o presupone, la totalidad de la materia de la que se obtienen los predicados posibles: el "entero acopio de la materia de la cual se pueden tomar todos los predicados posibles de las cosas".

${ }^{63}$ El texto de Kant dice: "de todos los predicados opuestos posibles se encuentra en su determinación uno, a saber, aquel que pertenece absolutamente al ser". (B 604.) Pero el mismo Kant había enseñado, ya en 1763, que los dos miembros de la oposición tienen un valor positivo (Negative Größen, Ed. Acad. II, 169). En verdad, la determinación mediante predicados opuestos debería reservarse solamente para las cosas finitas, en cuyo concepto no están incluidos todos los predicados. Esta determinación (de aquellas cosas que no son el ideal mismo) no puede efectuarse a priori. Cfr. B 605: "y la determinación omnímoda de toda cosa se basa en la limitación de ese todo de la realidad, al atribuirse a la cosa algo de la realidad, siendo excluido lo restante... " Por el contrario, el objeto de la razón debe ser "determinable integramente por principios"; la "intención de la razón con su ideal es [...] lả determinación omnímoda según reglas a priori". (B 599, el subrayado es mío.)

64 B 601 . Contra esto se podría invocar una objeción planteada ya por Kant: las realidades podrán muy bien ser puras afirmaciones sin mezcla de negación alguna, y gracias a ello podrán ser compatibles entre sí; ello significa que el concepto del ens realissimum es un concepto lógicamente posible, ya que no contiene contradicción (las contradicciones surgen al coincidir en un concepto afirmaciones y negaciones de los mismos predicados). Pero con ello no se ha demostrado la posibilidad real del ens realissimum: las realidades, aunque no sean contradictorias entre sí, pueden muy bien estar en una relación de repugnancia real. ( $C f$ r. Fortschritte der Metaphysik, Ed. Acad. XX, 302.)

A ello hay que responder que en la repugnancia real las realidades no se anulan entre sí; anulan los efectos de las realidades opuestas, (Neg. Gross., Ed. Acad. II, 172 y 175). Por tanto la repugnancia real no es objeción para la posibilidad de un ens realissimum. Por ello dice Kant que el ens realissimum es fundamento y no conjunto de toda la realidad (B 607): contiene todas las realidades, indiferente a la oposición real, solamente cuando es fundamento. 
El ideal no es mera idea, sino que es un objeto determinado por la idea; pero al afirmar esto nos encontramos con una declaración del mismo Kant, que parece quitarle a este pensamiento toda legitimidad. Kant escribe:

Pues la razón tan sólo la pone [a la idea de la omnitudo realitatis], como concepto de toda la realidad, por fundamento de la determinación completa de las cosas, sin exigir que toda esta realidad esté objetivamente dada y que sea ella misma una cosa. Ésta última es una mera invención, por la cual resumimos y realizamos lo múltiple de nuestra idea en un ideal, como ente singular; para lo cual no tenemos legitimación alguna, ni siquiera para suponer la posibilidad de una hipótesis tal, pues todas las consecuencias que se siguen de tal ideal no afectan para nada a la determinación omnímoda de las cosas en general, sólo para la cual se necesitaba la idea; ni tienen la más mínima influencia sobre ella. ${ }^{65}$

Claramente opone Kant aquí el concepto (la idea) a la cosa (el ideal), y muestra que la idea queda justificada por su función de condición de la determinación omnímoda, pero que el ideal no es necesario para esa función y que, por consiguiente, el ideal no posee aquella justificación transcendental. ¿Significa esto que debemos abandonar el ideal transcendental, por ser un pensamiento insostenible, y que debemos quedarnos solamente con la idea?

Lo injustificable, según el pasaje de B 608 recién citado, era suponer que el ideal estaba dado objetivamente. Fero no por ello debemos abandonar el ideal transcendental como si fuera un pensamiento insostenible. El mismo Kant se manifiesta contrario a eso: "estos ideales, por más que no se les pueda dar realidad objetiva (existencia), no deben considerarse por ello quimeras. . "66 Esto nos impone la tarea de encontrar algún modo de considerar el ideal como cosa y a la vez como algo no dado, sino meramente pensado: precisamente como un "objeto que se encuentra solamente en el pensamiento". 67

Precisamente esta formulación nos da la clave para la solución de la dificultad. El ideal es objeto, pero sólo objeto en la idea. ${ }^{68}$ Antes de ocuparnos de la función del objeto en la idea, vamos a considerarlo (a éste) en sí mismo y vamos a plantearnos la pregunta de qué clase de objeto se trata.

La idea que tiene a este objeto en la idea por contenido no se refiere por ello a un objeto independiente de ella misma; una eventual referencia del concepto de la razón a un objeto independiente no podríamos justificarla:

65 B 608 .

66 B 597.

67 B 606.

68 Cfr. H. Heimsoeth, Transzendentale Dialektik, p. 604: "El 'Ideal de la razón pura' resulta ser [... ] un 'objeto en la idea'... " La expresión "objeto en la idea" se presenta y se define en B 698; compárese B 724 s. 
"su realidad objetiva no ha de consistir en que se refiera directamente à un objeto (pues en tal significación no podríamos justificar su validez objetiva)". ${ }^{69}$ El objeto en la idea no tiene, por lo tanto, realidad efectiva: "Este ente de razón [... ] no se supone absolutamente, y en sí mismo, como algo efectivamente existente. . " $" 70$ El modo de ser de este objeto se asemeja al de los objetos imaginarios; ${ }^{71}$ pero no podría ser él mismo un objeto imaginario (para lo cual se requeriría la intervención de la sensibilidad, que aquí no cumple función alguna); sino que es el análogo de un objeto.

El objeto en la idea tiene realidad objetiva. Pero ello no hace que sea un objeto efectivamente existente y correspondiente a la idea; sino que la realidad objetiva que posee se opone a la realitas actualis sive formalis. ${ }^{72} \mathrm{Se}$ trata de una realidad que es solamente un contenido temático del concepto, y cuya referencia a algo que exista fuera del concepto no se puede ni afirmar ni negar sin otras pruebas. ${ }^{73}$

69 B 698.

70 B 709. Cfr. B 707: "Si miramos el objeto transcendental de nuestra idea, vemos que no podemos suponer su existencia efectiva en símisma según los conceptos de realidad, sustancia, causalidad, etc."

71 B 698: "en cuanto que el objeto de la experiencia se deriva, por decirlo así, del objeto imaginario de esa idea, como si fuese su fundamento o causa".

72 Es una realidad objetiva como la que menciona Descartes en la Meditación tercera: Oeuvres de Descartes, publicadas por Charles Adam \& Paul Tannery. Meditationes de prima philosophia VII, nueva presentación, en coedición con el Centro Nacional de la Investigación Científica, Vrin, París, 1964, pp. 40 y 41 . Véase Étienne Gilson, Études sur le rôle de la pensée médiévale dans la formation du système cartésien, 3a. ed, libreria filosófica J. Vrin, París, 1967 (1930), pp. 203 s.: "En soi, l'idée d'une substance n'est ni plus ni moins une idée que celle d'un accident, l'idée de Dieu n'est qu'un mode de ma pensée comme l'est l'idée de la matière; mais dans ce qu'elles représentent, ces idées ont une valeur très diverse, car l'iđée de la substance contient objectivemente beaucoup plus de réalité que celle de l'accident et celle de Dieu plus que celle de la matière. Sans doute, cette réalité objective n'est pas de même ordre que celle des choses qu'elle représente, mais elle lui est exactement proportionnelle. De toute façon, on ne peut pas dire qu'elle ne soit aucunement une réalité $[. .$.$] Ce contenu n'est donc pas rien,$ et comme il n'y a pas de milieu entre rien et quelque chose, c'est quelque chose." Gilson refiere la expresión "réalité objective" a la tradición escotista (loc. cit., p. 204 nota). Dinu Garber ha mostrado que el concepto de realidad objetiva, en la filosofía de Descartes, sólo puede aplicarse legítimamente a la idea de Dios; véase Dino Garber, "Realidad objetiva y grados de realidad objetiva en la Tercera meditación de Descartes: un solo caso posible de aplicación", en Revista venezolana de filosofía, no. 23, Caracas, 1987, pp. 39-53, aquí p. 49.

${ }^{73}$ Cfr. Eustachio a Sancto Paulo, Summa philosophica quadripartita, de rebus Dialecticis, Moralibus, Physicis et Metaphysicis, Authore, Fr. Eustachio a Sancto Paulo, a congregatione Fuliensi, 2 vols. in-8, Carolus Chastellain, Parisiis, 1609, IV, 17-19: "Esse objective in intellectu nihil aliud est quam actu objici intellectui cognoscenti, sive illud quod objicitur cognoscendum vere sit in intellectu aut extra intellectum, sive illud vere non sit [...] At vero quaedam sunt quae nullum habent aliud esse praeter istud objectivum seu esse cognitum ab intellectu, et haec dicuntur entia rationis." (Citamos según Étienne Gilson, Index Scolastico-cartésien, 2a. ed., revisada y aumentada; auțorizada por el autọr, librería filosófica J. Vrin, París, 1979 (1913)). 
Sin embargo, el objeto en la idea no es un producto caprichoso de la razón, sino que es el objeto de una suposición necesaria. La necesidad de esta suposición se basa en su imprescindible función como esquema que hace posible la unidad sistemática. ${ }^{74}$

Mientras que los principios de homogeneidad, de especificación y de continuidad ${ }^{75}$ se referían a todos los fenómenos y se podían aplicar dentro de cualquier ciencia empírica, las ideas se refieren a dominios de la experiencia determinados. La idea de alma, por ejemplo, se emplea como principio regulativo respecto de "todos los fenómenos, acciones y receptividad de nuestro espíritu". ${ }^{76}$

Esta determinación más estricta, en comparación con los principios, la reciben las ideas al ser pensadas en relación con un objeto (es decir, al ser pensadas como conceptos de un objeto). Este objeto es precisamente el objeto en la idea.

La forma de objeto la obtiene el objeto-en-la-idea de los conceptos puros del entendimiento. La aplicación de los conceptos puros del entendimiento a las colecciones completas de condiciones pensadas en las ideas, produce una síntesis de esas colecciones en la forma de un objeto; por cierto que esta síntesis es sólo pensada, y carece de todo dato de la sensibilidad; por lo tanto, no produce un objeto en sentido propio, sino solamente un objeto en la idea. Habiendo tres tipos de colecciones completas -elaboradas según los tres tipos de silogismos- se obtendrán así tres objetos de esta especie: alma, mundo y Dios.

La función de estos objetos-en-la-idea es la de servir como esquemas para efectuar la unidad sistemática racional de la multiplicidad empírica. ${ }^{77}$ En el caso particular del ideal de la razón, acabamos de ver que su función no es la de producir la determinación omnímoda de las cosas singulares (función para la que, según Kant; bastaba la idea). La función del ideal no es la de ser principio de individuación. Más bien a la inversa, el texto de Kant dice que la determinación omnímoda es necesaria para producir el ideal mismo. Pero la regla para que la determinación de las cosas singulares

74 B 709: "Pero la razón no puede pensar esta unidad sistemática de otro modo, que dándole a su idea a la vez un objeto, que no puede ser dado, empero, por experiencia alguna." Cfr. B 710: "esta cosa transcendental es tan sólo el esquema de aquel principio regulativo por el cual la razón, en cuanto está en su poder, procura extender la unidad sistemática a toda la experiencia."

75 B 686.

76 B 700.

77 Béatrice Longuenesse (op. cit., p. 535) también relaciona la función regulativa del ideal con el esquematismo; pero no señala diferencia alguna del esquematismo del entendimiento (por el que objetos empíricos singulares se subsumen en conceptos puros) y el esquematismo de la razón (por el que la totalidad del conocimiento se integra en un sistema). 
se integre en una unidad total de la realidad (esto es, la regla para que la determinación ponga en relación al ente singular con la totalidad de la realidad entendida como una unidad), está dada por la regla de la acción de la razón, de producir al ens realissimum por determinación omnímoda. El ens realissimum es un esquema de la razón, que suministra la regla para el uso de la determinación integral de las cosas singulares en vista de la integralidad de tal determinación. La misma acción por la cual la razón produce, en la multiplicidad meramente pensada, el objeto-en-la-idea que es el ens realissimum, es la acción que se aplica a la multiplicidad dada de las cosas singulares, para unificarla en vista de un sistema único racional (el cual se propone así por meta del uso del entendimiento): "la aplicación del concepto del entendimiento al esquema de la razón no es un conocimiento del objeto mismo [... ] sino tan sólo una regla o principio de la unidad sistemática de todo uso del entendimiento". ${ }^{78}$ Se obtiene así "el procedimiento [... ] según el cual el uso empírico y determinado del entendimiento en la experiencia puede concordar íntegramente consigo mismo, al ponerlo en conexión con el principio de la unidad completa..."79

A cada una de las tres ideas transcendentales le corresponde su propio objeto en la idea. La función de éste es, como ya se dijo, servir de esquema para la aplicación de la síntesis pensada en la idea, a la multiplicidad empírica de los conocimientos del entendimiento. ${ }^{80}$ Ésta es, en particular, la función regulativa del ideal de la razón.

80 Son esquemas del concepto de una cosa en general, sólo que ordenados "según las condiciones de la máxima unidad de la razón" (B 698), esto es, según la máxima de la totalidad. 